se reconocerá el derecho de Berceo a la paternidad del Alexandre. Tengo confianza en que la versión reconstruida incluida en estas páginas constituirá un gran paso en esta dirección" 34 .

Gilberto TRIVIÑOS

Universidad de Concepción, Chile.

\title{
MÚSICA Y CANCIÓN EN EL TEATRO DE LOPE DE УEGA
}

Noël Salomon, en sus imprescindibles Recherches sur le thème paysan dans la "comedia" au temps de Lope de Vega, dedica sesenta páginas a estudiar la música en las obras del Fénix. Pero lo que realmente preocupaba a Salomon era saber si los instrumentos musicales empleados en esas obras eran verdaderos instrumentos rústicos y si los cantos y danzas que en ellas aparecen son los mismos, que, hacia 1600 , practicaban los campesinos. Apenas si le interesaba otra cosa; de ahí que sólo muy marginal y muy esporádicamente Salomon se refiera a otros aspectos. Aspectos que, para mí, son capitales.

Desgraciadamente, del teatro de Lope - un teatro al que, y refiriéndose a muchas de las comedias "rústicas", el mismo Salomon define como "piezas líricas mezcladas de música y danza" - no nos ha llegado más que el texto. Y, sin embargo, sabemos la decisiva importancia que la danza y la música tienen en muchas de sus obras. Incluso las acotaciones son escasas $\mathrm{y}$, en bastantes casos, imprecisas. En la comedia hagiográfica Santa Teresa de Jesús la acotación dice: "Cantan dentro". Y en seguida Teresa pregunta: “¿Escuchásteis la canción?”. Y más adelante, la rúbrica será: "Cantan otra vez"; y la pregunta:

¿Habéis, por ventura, oído

las dulces voces que yo?

Bien es verdad que sólo la futura Santa oye las canciones; pero esto es otra cuestión. Lo cierto es que las acotaciones indican claramente el canto, y que nosotros no sabemos cuál haya sido. En El rústico del cielo, Francisco dice:

\begin{tabular}{|c|c|}
\hline & $\begin{array}{l}\text { Ea, todo el mundo diga } \\
\text { con mucho gusto y placer } \\
\text { unas coplas que hemos hecho } \\
\text { con ayuda de vecinos. }\end{array}$ \\
\hline 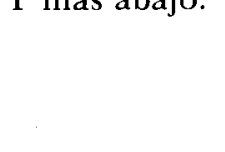 & $\begin{array}{l}\text { Ea, todo el mundo diga } \\
\text { con mucho gusto y placer: } \\
\text { ¿Qué haré para me salvar? } \\
\text { Creer y obrar. }\end{array}$ \\
\hline
\end{tabular}


Éstos son los versos finales del segundo acto; pero van seguidos de esta acotación: "Todos respondan, y diga el hermano las coplas solo y respondan los demás". Es claro que lo que los demás tienen que responder son los dos últimos versos mencionados; pero, ¿cuáles son las coplas? En la antes citada Santa Teresa de Jesús nos encontramos con la siguiente escena:

Danzan Teresa y D. Juan

VALLE.- ;Buen aire!

D. RAMIRO.- $\quad$ En extremo danza; ella se lleva la palma.

D. DIEGO.- Medida me toma al alma el compás de esta mudanza.

VALLE.- Es lo que hay que desear.

TERESA.- Cansada quedo, a fe mía.

Pero, ¿quién canta o toca, si nada se indica ni figuran músicos en el reparto? En general, nos encontramos con fórmulas del tipo de "toquen los músicos", "canten", "músicos", "tocan, cantan y bailan", etc. A las veces, Lope se desentiende. En el tercer acto de Amor secreto hasta celos el Príncipe va a ver a una dama; Octavio le pregunta si los músicos deben cantar.

PRÍNCIPE.- $\quad$ Canten, que es seña con que me dijo una dueña que a la ventana saldría.

Cantad por que salga el día; será la noche pequeña.

Y la indicación de Lope reza: "Los músicos canten lo que quisieren". Pero, ¿qué era lo que cantaban esos músicos? En buen número de casos, canciones en boga. D. Diego, en Por la puente, Juana, pregunta:

Señores músicos, ¿saben

la letra que agora se canta: Por la puente, Juana, que no por el agua?

MUSI.- Sí sabemos.

Y de esta forma sabemos también nosotros que la cancioncilla que dio título a la comedia, y que habría de ser recogida por Correas en su Vocabulario, era popular hacia 1624-25, si aceptamos la datación propuesta por Morley y Bruerton. En la "acción en prosa" La Dorotea, III, p. 247, Julio dice: “¿qué espectáculo, qué música, qué vino como ella misma, para que descanse mi amado preso, como dize la letrilla que agora cantan?". Claro que la seguidilla citada:

Galeritas de España parad los remos, para que descanse mi amado preso 
era conocida, por lo menos, treinta años antes, pues que figuraba ya en Los cancionerillos de Munich (1602). No olvidemos, no obstante, que Lope dice en la dedicatoria al Conde de Niebla: "Escriví La Dorotea en mis primeros años..."

En otras ocasiones Lope es menos explícito respecto a la popularidad de la canción. En El galán escarmentado, Ricarda y Roberto mantienen el siguiente diálogo:

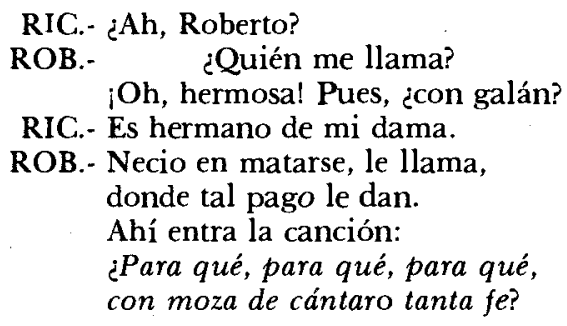

Algo semejante ocurre en $E l$ príncipe perfecto, $2^{\mathrm{a}}$ parte, cuando Tristán dice:

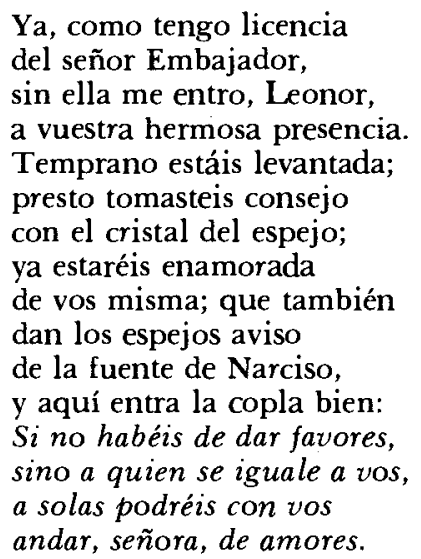

La canción no era nueva: Pedro de Padilla la había recogido en su Tesoro (1580). Pero en otras ocasiones Lope nos da la canción sin anunciarla en modo alguno. Cuando Lucrecia, en La mal casada (para Morley y Bruerton escrita entre 1610-1615), se disculpa ante $D$. Juan de sus dos casamientos, debidos al consejo de su madre " a quien tanto ofusca / la codicia del dinero", nos suelta, de sopetón, una canción que debía de ser coetánea, ya que la encontramos en un ms. fechado en 1620 :

\footnotetext{
LUC.- De las desdichadas yo soy la una; sigueme la rueda de la fortuna.
} 
Treinta y cuatro años, por lo menos, tendría de vida otra cancioncilla que Lope recoge en una comedia autógrafa (Del monte sale quien el monte quema, fechada el 10-X-1627), puesto que aquélla había aparecido ya en el Ramillete de flores, publicado por Pedro de Flores en Lisboa, 1593. En dicha obra, habla Narcisa:

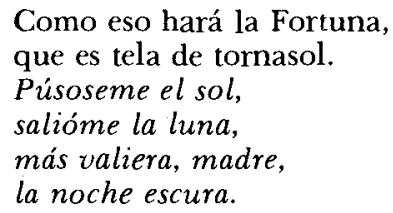

Más antigua, sin embargo, es otra canción que figura en una obra bastante anterior. La canción la recoge el ms. 17.698, fechable entre 1560 y 1570 , en tanto que Morley y Bruerton sitúan La hermosura aborrecida entre 1604 y 1610 . En ella Belardo, como su hija le pidiera un barbero que la sangrara, comenta:

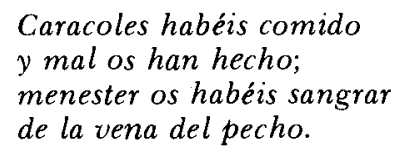

Para los tantas veces citados Morley y Bruerton El engaño en la verdad es de "incierta autenticidad", aunque añaden que "si es de Lope, es de 1612. 1618". En ella Danteo llega a la aldea con noticias frescas para Leonardo. Y esto es lo primero que dice:

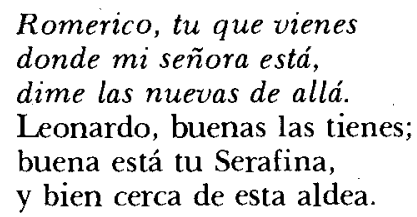

Pero los tres primeros versos de Danteo son, ni más ni menos, una canción del siglo XV, canción que, con música de Juan del Encina, había sido incluida en el Cancionero musical de Palacio.

Lo que acabo de exponer permite ya un doble planteamiento: textual y musical. Respecto a los textos - y hasta este momento estoy hablando sólo de canciones conocidas, no de las creadas por Lope-nos encontramos con lo siguiente: a) Lope recoge canciones populares en ese momento y así lo hace saber; $b$ ) Lope nos anuncia la aparición de una letra, pero sin indicarnos si es conocida o no; y c) Lope introduce la canción sin indicación de ningún tipo. Este último caso plantea, evidentemente, un problema serio: el de su reconocimiento como canción, primero, y el de su identificación, después.

Pero no es de esto de lo que voy a ocuparme aquí, sino de algo que, a partir de ahora, tendremos que tener siempre presente cuando hablemos de las canciones, porque es inseparable de las mismas. 
Me estoy refiriendo al ya apuntado aspecto musical. Y es que es éste, quizá, el que más problemas plantea. No me refiero a la música de esas canciones. Muchas, como acabamos de ver, eran populares; viejas o modernas, pero conocidas. Para otras, invención de Lope, escribieron partituras músicos afamados, como Juan Blas. No; no me refiero a esto, sino a algo, para mí, no menos preocupante: ¿cuándo se cantaban las canciones? Porque Lope, aun olvidándonos de la escasez y parquedad de sus indicaciones a este respecto, acumula las dificultades por otro lado: el de las funciones de la propia canción. Recordemos uno de los ejemplos citados: el de Lucrecia en La mal casada quejándose, ante D. Juan, de su fortuna:

$$
\begin{aligned}
& \text { De las desdichadas } \\
& \text { yo soy la una; } \\
& \text { sigueme la rueda } \\
& \text { de la fortuna. }
\end{aligned}
$$

Toda su desdicha viene de esos casamientos realizados por mor de la codicia de su madre. Tiene razón para quejarse. Y la canción encaja tan perfectamente que podría pasar desapercibida. Pero la cuestión, ahora, es ésta: reconocidos e identificados esos versos como canción, ¿̇debemos dedu cir que se cantaban? Porque, recordémoslo: Lope no hace la menor indica ción. No dice absolutamente nada. Y no creo que siempre se trate de olvidos. Tenemos que tener en cuenta la función de esas letras. Todo el mundo sabe cuál es la del cantarcillo de El caballero de Olmedo. Pero voy a ejemplificarlo, para que se note bien, con uno de los traídos aquí. Ya dije antes que, efectivamente, los músicos cantaban, a petición de D. Diego, la letra que éste les preguntaba si conocían: Por la puente, Juana, / que no por el agua. ¿Por qué? $\mathrm{D}^{\mathrm{a}}$ Juana, loca de celos de $\mathrm{D}$. Diego, se halla cerca del puente de Alcántara. Al llegar al río se encuentra con el Marqués y D. Diego que están subiendo a una barca. El Marqués le ofrece sitio en ésta "para llevarla / donde no la valgan bríos / ni condiciones villanas". Y D. Diego, para avisarla del peligro que corre, utiliza la canción.

Es casi seguro, al menos así lo creo, que, pese a que Lope no diga nada, buena parte de los textos citados se cantasen en la escena. Blanca, en Lo que pasa en una tarde, dice:

Ya no lo puedo sufrir.

Mucho del alma me cuesta

el querer disimular

la causa de tanta pena.

Hierbas de Amor me mataron,

flechas tiene Amor con hierbas;

pero las mismas agora

me sirven y me remedian.

Como eran verdes entonces puse mi esperanza en ellas, porque hay mil cosas fingidas que parecen verdaderas.

No me aprovecharon, madre, las hierbas; no me aprovecharon $y$ derramélas. 
Inesperadamente, Lope coloca aquí una bien conocida seguidilla. Ha ido preparando el terreno hablando de las "hierbas del Amor". Y es de suponer que se cantase. Pero no dice nada.

Bien conocida también era la cancioncilla que aparece en El casamiento por Cristo:

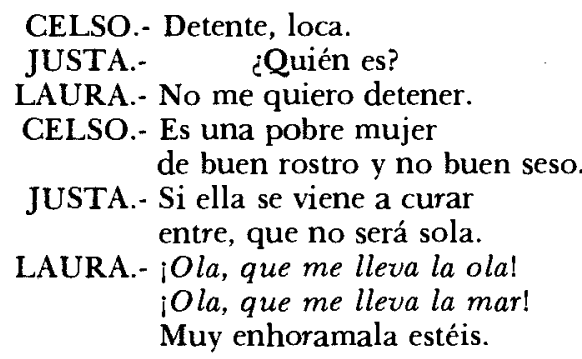

Veintinueve versos después, siguiendo el diálogo, Laura vuelve a utilizar la canción. Tampoco hay indicación alguna por parte de Lope. Peroel hecho de que, en el texto citado, la presente como una mujer de "no buen seso", propicia y hace que no resulte extraño el que Laura responda cantando. Pero otros casos son mucho más dudosos. En La burgalesa de Lerma, comedia fechada en 1613, D. Félix está enamorado de Clavela, quien le da celos con el Conde Mario. D. Félix se apartó de ella, decidido a dejarla; pero volvió. $\mathrm{Y}$ al ir a visitarla la encontró con el Conde, por lo que ahora está aún más celoso. He aquí el diálogo que mantiene con Poleo, su criado:

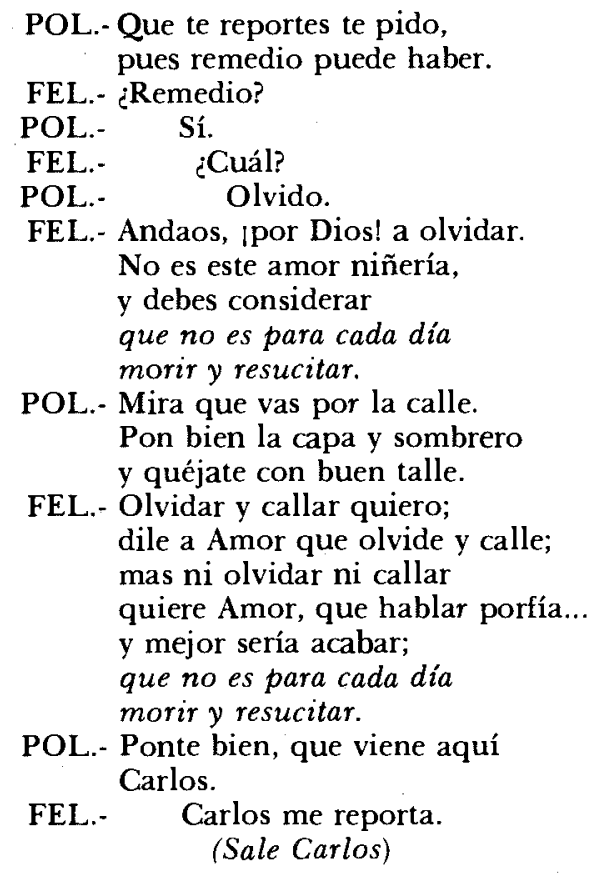


CAR.- A buscarte vengo.

$$
\text { FEL.- ¿A mí? }
$$

CAR.- A ti, ipor Dios!, y te importa.

FEL.- Si me importa, Carlos, di.

CAR.- ¿Qué es esto?

POL.- De visitar esa Clavela salía.

FEL. - Dile, si lo has de contar, que no es para cada día morir y resucitar.

Pues bien; esos dos versos que reiteradamente pronuncia D. Félix no son sino los finales de una canción:

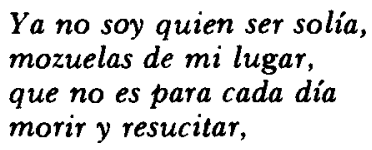

recogida por un ms. de 1603 , pero que unos pocos años antes, en 1587 , recordaba Camoens en sus Enfatrioes. ¿Eran cantados en la obra de Lope? ¿Podemos concederle algún valor al hecho de que, una vez enunciados por vez primera, aparezcan, como si un metrónomo les estuviese marcando los tiempos con precisión, cada ocho versos? Y digo esto porque más adelante veremos otro ejemplo en el que concurren circunstancias semejantes y respecto al cual me inclino por el canto en la escena. Pero para el que ahora comento tengo muchas dudas. La aplicación que Lope hace aquí de la canción, ¿conllevaba una función musical, desconocida por nosotros hoy, independiente de la textual? Quiero decir: si estas referencias tenían, entre sus connotaciones, la musical. Tengo por seguro que el público de Lope reconocía inmediatamente estas canciones y hasta es posible que, a las veces, las tararease al mismo tiempo que eran cantadas en escena. Pero en casos como éste, y otros que voy a exponer ahora, ¿qué ocurría? Porque si hay ocasiones en que un verso, generalmente el primero, de una canción recordada por Lope tiene una clara función referencial total, también es posible que estos versos puedan remitir a una música determinada y, oor tanto, entrañar unas connotaciones musicales concretas.

El Romancero de Barcelona recogía la siguiente canción:

$$
\begin{aligned}
& \text { Mañanitas floridas } \\
& \text { del mes de mayo, } \\
& \text { despertad a mi niña } \\
& \text { no duerma tanto, }
\end{aligned}
$$

y en El acero de Madrid, act. I, dice Beltrán:

Las aves cantan ya

a Belisa con voz suave:

Mañanitas floridas

del mes de mayo,

recordad a mi niña,

no duerma tanto. 
Veinte versos después es Lisardo quien cita los dos versos finales. Riselo, que continúa el diálogo, incluye también dieciocho versos después, los dos citados, aunque con variación: Recordad a mi tía; y por último vuelve Beltrán, con otros veinte versos y los dos ya conocidos, sólo que con fin claramente burlesco: Recordad mi fregona. Pues bien; ni estos versos, ni la cancioncilla completa, llevan indicación alguna de que se cantasen. Es de suponer que sí, y más si tenemos en cuenta la parte final del parlamento de Lisardo:

$$
\begin{aligned}
& \text { Arroyuelos cristalinos, } \\
& \text { rüido sonoro y manso, } \\
& \text { que parece que correis } \\
& \text { tonos de Juan Blas cantando, } \\
& \text { porque ya corriendo apriesa, } \\
& \text { y ya en las guijas despacio, } \\
& \text { parece que entrais con fugas } \\
& \text { y que sois tiples y bajos, } \\
& \text { recordad a mi niña, } \\
& \text { no duerma tanto. }
\end{aligned}
$$

Los versos de la canción aparecen dentro de una especie de contexto musical; tonos, fugas, tiples, bajos... Todo parece indicar que el cantarlos ahí sería adecuado. Pero veamos ahora el parlamento de Beltrán:

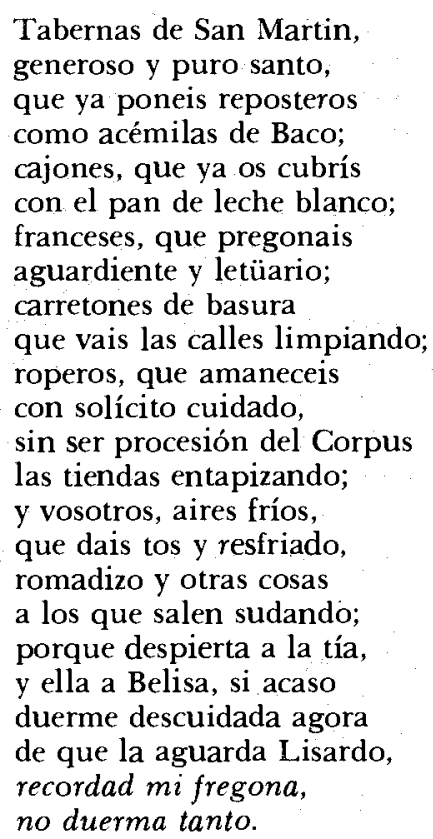

Todo esto es claramente burlesco; desde la alusión a San Martín, es decir, a San Martín de Valdeiglesias, "generoso y puro santo", famoso por sus vinos, pasando por la tos y el romadizo, hasta el final, todo, repito, es un contexto burlesco muy al punto para insertar la variante mi fregona. Si recordad a mi niña / no duerma tanto, respondía a la forma canónica y a un 
motivo claro, ¿qué efecto tenía que producir en los espectadores oír la canción ahora y, además, deformada? A lo que parece, Lope buscaba la comicidad por muy diversos caminos.

Esta misma canción es contrahecha "a lo divino" por Lope en $E l$ Cardenal de Belén. Tras la indicación "canten", viene:

\author{
Mañanicas floridas \\ del frío invierno, \\ recordad a mi Niño, \\ que duerme al hielo. \\ PASCUAL. Mañanas dichosas \\ del frío diciembre, \\ aunque el cielo os siembre \\ de flores y rosas, \\ pues sois rigurosas, \\ y Dios es tierno... \\ MÚSICA.- Recordad a mi Niño, \\ que duerme al hielo.
}

Aquí está bien claro: al final se repiten los versos porque se trata de un villancico. Y también está claro que lo que dice Pascual es la glosa. Y ha de ser igualmente claro que lo que dice Pascual, aunque Lope no indique nada, tenía que ser cantado. Pascual hace, por tanto, de solista. Así es la forma normal del villancico o de la canción zejelesca: un coro -aquí los músicos - y un solista - Pascual- Pero esta canción nos plantea otro problema: su música. ¿Se cantaba con la misma música que la canción original? ¿Estamos aquí ante uno de los casos de las "vueltas a lo divino" en los que una canción determinada se contrahacía para cantar "al tono de"'? La pregunta se hace más inquietante si el planteamiento lo llevamos un poco más lejos. Recordemos una canción citada antes:

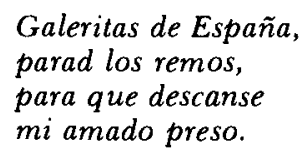

Todo parece indicar que, sobre esta misma, hizo Lope la que figura en Amar, servir y esperar:

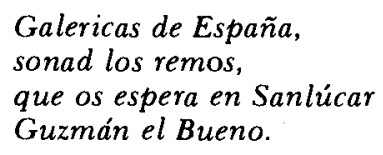

En este caso, ¿era también cantada "al tono de”"? ¿Se cantaban de este modo las nuevas versiones que Lope hacía de una canción ya conocida? No se nos dice nada.

Veamos otro caso, aún más difícil de interpretar. Lo encontramos en el act. III de Porfiando vence amor (c. 1624-1626): 
MÚSICOS.- Las sierras eran altas y malas de subir; los caños corren agua $y$ dan en el toronjil.

FELINO.- Pardiez, amo y señor nuestro, que nos debéis grande amor.

CARLOS.- Amigos, todo el mayor que puede mi alma os muestro.

SIRENA.- Conteis desde aqueste abril mil años.

ALCINDO.- ¿Mil? Dos mil sean.

FELINO.- Justamente en vos se emplean.

FABIO.- $Y$ dan en el toronjil.

LUCINDA.- Entre tantos parabienes, ¿no tendrá lugar el mío?

CARLOS.- Y entre los pies de ese brío toda mi esperanza tienes. Llega, Lucinda gentil, porque con tiernos abrazos me dan parabién tus brazos.

FABIO.- $Y$ dan en el toronjil.

Todavía, a lo largo del diálogo, Fabio volverá a repetir el verso final de esta cancioncilla que Lope ha modificado ligeramente, pero que había aparecido ya en 1552 en el Libro de música del vihuelista Diego Pisador. Lope sigue una versión próxima a la recogida por Pedro de Padilla en 1580. Pero la cuestión es saber si ese verso suelto que machaconamente repite Fabio, venga o no a cuento, se cantaba. ¿Actuaba él también como solista? En este caso, ¿daba pie para que volviera a entrar el coro, es decir, los músicos? Nada nos indica Lope, en ningún sentido.

Pero quizá los casos más claros de varias voces y un solista sean los famosos del leit-motiv, como el celebérrimo de La dama boba: Deja las avellanicas, moro, / Que yo me las varea ré. En La hermosu ra aborrecida, los músicos repiten siempre el mismo verso:

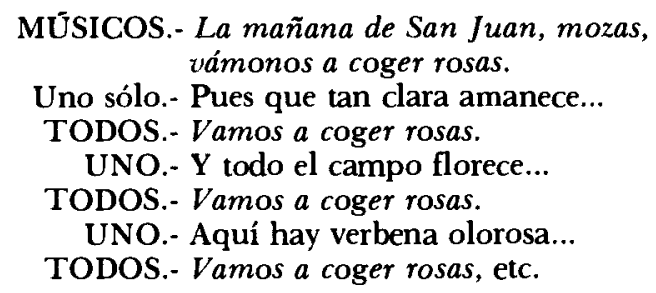

Aquí sí se nos dice claramente cuándo ha de intervenir el solista y cuándo el coro. Lo mismo ocurre en La burgalesa de Lerma (1613), en la que, dentro de una larga escena de canto y baile, al solista le responden todos con el segundo verso del estribillo:

UNO.- Niña, guárdate del toro.

TODOS.- Que a mi mal ferido me ha.

UNO.- Guárdate del toro, niña.

TODOS.- Que a mi mal ferido me ha. 
UNO.- Es amor que desatina.

TODOS.- Que a mi mal ferido me ha.

UNO.- Arma la frente de lira.

TODOS.- Que a mi mal ferido me ha, etc.

En otras ocasiones, en cambio, Lope no es tan explícito; pero cabe suponer que el recurso sería el mismo. En Ello dirá (c. 1613-1615) el autor sólo indica: "Música de labradores y baile", pero la presencia del leit-motiv hace presumir el mismo tratamiento musical:

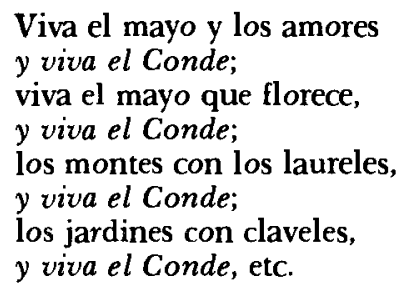

Y esto nos lleva a otra pregunta: a cómo se cantaban estas canciones. A las veces, suene dentro o en escena, se trata de un solista. Pero en la mayoría de los casos Lope dice, simplemente, “cantan", “canten”, "músicos", "músicos canten", etc. El empleo del plural nos indica que son varios. En ocasiones puede tratarse de un canto alterno entre dos grupos de músicos, como ocurre en Amar, servir y esperar (entre 1624-1635), act. II. La acotación dice: "Dentro música, guitarra, sonajas y bulla". Y unos cantan:

Vienen de Sanlúcar, rompiendo el agua, a la Torre del Oro, barcos de plata,

a lo que responden desde otra parte con la ya citada Galericas de España..., y vuelven los primeros con:

\title{
Barcos enramados van a Triana; el primero de todos me lleva el alma,
}

para rematar los segundos:

\author{
A San Juan de Alfarache \\ va la morena, \\ a trocar con la flota \\ plata por perlas.
}

Las seguidillas solían cantarse así, una tras otra, aunque en el teatro no sea muy frecuente. Pero, sin embargo, en El desconfiado (1615-1616), son siete seguidas las que Lope introduce.

La Adversa fortuna de D. Bernardo de Cabrera, que Morley y Bruerton consideran dudosa, presenta un caso curioso. Vamos a verlo: "Salgan los que pudieren tañendo y cantando. 
MÚSICOS.- Las olas del Ebro llenas de oro van en la noche alegre del señor San Juan. Barcos enramados de verde arrayán rompen en el Ebro líquido cristal. Abundan las damas que en la puente están en la noche alegre del señor San Juan".

Y luego viene el diálogo:

D. BERNARDO.- ¿Quiénes serán aquestos? ROBERTO.- Músicos que van al río.

MÚSICOS.- Ebro, corre apriesa por llegar al mar, porque el bien y el agua no saben parar.

Que alegres cosas trocadas están en la noche alegre del señor San Juan.

D. BERNARDO.-Roberto, dos versos de aqueste cantar: "Porque el bien y el agua no saben parar" me han dado gran pena.

ROBERTO.- ¿En agüeros das en la noche alegre del señor San Juan?

D. BERNARDO.-Fingidas sirenas que cantando estais mudanzas del tiempo, Dios os haga mal. Las obsequias vuestras, cual cisnes, cantad, en la noche alegre del señor San Juan. Después volveremos, vamos a rondar.

(Vanse los dos)

LAZARO.- A cantar porfían, como cantan mal.

D. LOPE.- Diles que se vayan.

LAZARO.- Váyanse a cantar en la noche alegre del señor San Juan otro poco al río.

LEONIDO.- Calle el ganapán, porque algún cobarde lo quiere estorbar.

D. LOPE.- ¡Vive Dios, villanos, 
que os haga callar!
LAZARO.- En la noche alegre
del señor San Juan.

La repetición, cada seis versos, de los dos de la canción: en la noche alegre / del señor San Juan, ¿puede indicar, como dije más arriba, que eran cantados? En este caso se trataría de un canto a varias voces simples, es decir, distanciadas unas de otras, pues tengamos en cuenta que, aparte de los músicos, los cantan Roberto, D. Bernardo, y Lázaro, este último dos veces. De todas formas, no parece probable; da la impresión más bien de ser un juego de recurrencias textuales y no musicales.

Pero si aquí no se trata de un canto polifónico, en otras ocasiones sí. En unas lo dice expresamente, como en La Serrana de la Vera (1598): "vienen baxando por lo alto Bartola, Turino, Antón, Corveo, villanos, por agua, cantando a cuatro voces". O en El rústico del cielo, en la que una acotación reza: "la música, a tres voces, reponda". En otras este estilo contrapuntístico debemos suponerlo. Tal ocurre en El Infanzón de Illescas, una obra considerada por Morley y Bruerton como "concluyentemente" no de Lope, en la que "salen Belardo, Tirreno Riselo, cantando este villancico". O en Los Benavides (c. 1598-1602) en la que la acotación reza: "Salen cuatro segadores y serán de los músicos". En Con su pan se lo coma (h. 1613-1614) la indicación es: "Salen los villanos músicos, Celio, Fabio, Da Elvira y Tomé". En Las almenas de Toro (1610-1613?) leemos: "Sale Da Sancha con el sombrero de paja y cuatro segadores; Nuño, Suero, Tello, labradores". Comentando esto, Noël Salomon (pág. 616) escribe: "Adivinamos de antemano, una vez más, que un cuarteto vocal o instrumental va a intervenir; de hecho, se puede notar qué los "segadores" anónimos introducidos en esta rúbrica no toman parte en el diálogo y que no abren la boca más que para cantar". Así acontece en bastantes ocasiones: los "segadores", los "villanos", los "pastores", etc., no son sino los músicos vestidos de tales.

Pero si en casi todos los casos que anteceden podemos suponer el canto, en otros no ocurre así. Cuando en el act. II de Donde no está su dueño, está su duelo nos encontramos con el siguiente diálogo:

SABINA.- Pisad con plantas de lana.

BANQUETE.- Pasito, quedito, amor,

no nos sienta el ruiseñor.

¿qué debemos pensar? Porque no nos hallamos ante un diálogo normal. Lo que aquí aparece como tal son partes de una canción que Lope ya había utilizado en El ruiseñor de Sevilla (c. 1604-1608). Y digo partes porque ocurre algo ciertamente sorprendente: el verso citado en primer lugar corresponde al quinto de la glosa; los otros dos son una adaptación de los dos versos finales del estribillo:

Si os partiéredes al alba quedito, pasito, amor, no espantéis al ruiseñor. 
Si os levantéis de mañana

de los brazos que os desean, porque en los brazos no os vean de alguna envidia liviana, pisad con planta de lana, quedito, pasito, amor, no espantéis al ruiseñor.

La cosa está clara. Son los versos finales de esta canción. De este modo, al sugerir Sabina el andar silencioso con "pisad con plantas de lana", lo que ha hecho es traer al diálogo, como si se tratase de un modismo y de manera aparentemente inocua, el último verso de la glosa. Banquete lo captó de manera inmediata y, al hacerlo, lo asoció con el estribillo. Muy hábil por parte de Lope. Quizá lo que estoy describiendo respecto a Banquete es justamente lo que pasó en la mente del Fénix. Pero la cuestión sigue ahí: ¿se cantaban estos versos? Sinceramente, creo que no. Para mí sólo son una cita y un puro juego verbal. Pero no se puede descartar tal posibilidad ni tampoco el valor que pudiera tener, por asociación, el añadido mental de la música.

Más difíciles aún de interpretar son ejemplos como el siguiente. En la segunda parte de El príncipe perfecto (h. 1616), Leonor y Tristán hablan de D. Lope, el enamorado de Leonor:

TRIS.- En la fuente está Leonor.

LEON.- Y cómo, si estoy mirando mis tristezas cuidadosa.

TRIS.- Hace que bebe, y celosa lava el cántaro llorando.

LEON.- Dile, Tristán, que me vea esta noche en mi ventana.

TRIS.- El vendrá a verla mañana y el sol que en ella desea.

LEON.- ¿Quiéreme bien? Que dudando lo estoy.

TRIS.- $\quad$ Amor hay aquí, cuando va Leonor ansí sus amigas preguntando.

LEON.- No te espante mi temor, ni que descanse contigo; pues hasta a las piedras digo: ¿vistes por allá mi amor?

TRIS.- Que no, respondo en rigor, y de tu temor lo arguyo; porque otro amor como el tuyo no le hemos visto, Leonor.

Como se ve, la canción se adapta perfectamente al diálogo; tanto, que más parece diálogo que canción. Y, sin embargo, era una canción vieja y bien conocida puesto que, sin el último verso - que se incorporará más tarde- ya la había utilizado Camoens: 


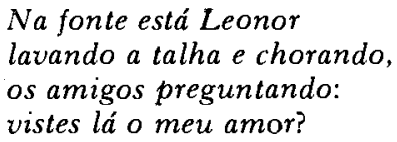

La versión de Lope, que es la misma del Marqués de Alenquer, no parece que se cantase aquí. La canción está embebida en el diálogo, con una técnica que Lope utilizó muchas veces ${ }^{1}$. No se trata tampoco de un alarde de virtuosismo. Todas las canciones de Lope tienen una función, que habrá que estudiar seriamente, dentro de la obra. Pero el problema que ahora se plantea aquí es el de saber si, en casos semejantes, estas canciones embebidas tienen, como ya indicaba más arriba, también una función musical. Porque el procedimiento puede complicarse mucho más. He aquí, como último ejemplo, parte del parlamento de un personaje de La hermosura aborrecida:

$$
\begin{aligned}
& \text {...que al pasar huyendo } \\
& \text { un arroyo limpio } \\
& \text { no haya miedo, madre, } \\
& \text { no haya miedo, digo, } \\
& \text { que por él tornase } \\
& \text { aunque su bullicio } \\
& \text { me tirase perlas } \\
& \text { de cristal rompido... }
\end{aligned}
$$

¿Qué hay aquí de particular? Sencillamente, que Lope ha embebido una canción famosa:

$$
\begin{aligned}
& \text { Bullicioso era el arroyuelo } \\
& \text { y salpicóme; } \\
& \text { no hayas miedo, mi madre, } \\
& \text { que por él torne. }
\end{aligned}
$$

Naturalmente, tal como está en el texto resulta incantable. Pero, ¿no habrá ahí, como acabo de apuntar, aparte la función textual de la canción, también una sugerencia musical? Tendríamos que conocer, en todos estos casos, la música de cada una de las canciones. Algo que, desgraciadamente, no ha llegado a nuestras manos.

No se acaban, con lo expuesto, los problemas. No sabemos, por ejemplo, si se cantaban los versos de una canción glosada a lo largo del diálogo. No sabemos, como decía más arriba, si las "recreaciones" o los "calcos" tenían música independiente de la canción original. Por otra parte, en las escenas en que los músicos figuran'y no intervienen, ¿cantaban algo no indicado en el texto? ¿Tocaban? Y si era esto último, ¿la música servía de fondo o subrayaba el texto? ¿Qué hacen los músicos en el act. II, esc $^{\mathrm{a}} 2^{\mathrm{a}}$, de El príncipe perfecto? ¿Qué en el act. II de Roma abrasada

\footnotetext{
'Sobre este aspecto, cf. mi ponencia "Sobre el cancionero teatral de L. de V.", en las Actas del primer congreso internacional sobre Lope de Vega. Para la mayoría de las canciones aquí citadas, cf. mi libro El cancionero español de tipo tradicional, Madrid, 1968. Quiero añadir, también, que para cada uno de los casos comentados abundan los ejemplos y, por último, que las referencias proceden de la $B A E$
} 
(1598-1600)? En el act. III de El Duque de Viseo (h. 1608-1609), el editor moderno se ve en la necesidad de anotar a pie de página: "Habiendo salido músicos en la esc. IV, los cuales después no han cantado ni hablado, es de suponer que se ha suprimido algo en las escenas anteriores a ésta". No lo creo así, porque los ejemplos abundan. Es, sencillamente, otra interrogante más; una de las muchas que, en este aspecto, y como ya hemos visto, Lope, el gran Lope, nos dejó. Con su despreocupación, con la a veces exasperante parquedad en las indicaciones cuando no olvido absoluto de las mismas, aquella rúbrica de "canten lo que quisieren" parece estar diciéndonos ahora: "piensen lo que quisieren". El vitalismo de Lope le imponía preocupaciones más urgentes. Preocupaciones que, ¿por qué no? podían traducirse en canción; en canción como aquélla, bellísima, de Santiago el Verde (1615):

Álamos del Soto, ¿dónde está mi amor? Si se fue con otro moriréme yo.

JOSẼ MARÍA Alín

\section{PROPÓSITO Y ORIGINALIDAD DEL APOLOGÉTICO DE JUAN DE ESPINOSA MEDRANO}

Aunque la fama del Apologético en favor de don Luis de Góngora es grande, pocos estudios particulares le han sido dedicados ${ }^{1}$. Generalmente se confunde su importancia histórica con su validez crítica, y su primera edición (Lima, 1662) es casi desconocida.

Según sabemos, Espinosa Medrano responde a una censura contra Góngora que aparece en los comentarios a Las Lusiadas de Faria y Sousa. Examinando éste el hipérbaton: que em terreno, / nam cabe o altivo peyto tan pequeno (Canto III, estrofa 94), dice lo siguiente:

No puedo cōtenerme, $\bar{q}$ no diga en tā buena ocasiō $\bar{q}$ hallandome adonde se hablò desto, en presencia de algunos sugetos de los $\overline{\mathrm{q}}$ tienen medio pie en los Tribunales, i medio en el Parnaso, i el otro en el ayre, assentarō $\bar{q}$ Dō Luis de Gōgora solamente era Poeta... Apretădoles por el lugar, o lugares, o misterio, o juizio, o alma poetica en $\bar{q}$ lo fundava, concurrieron (uno dellos, el màs nueuo, siedo mas viejo cō pertinacia) en $\overline{\mathrm{q}}$ aquel hyperbaton, i essotro

' Hasta donde tengo conocimiento, estos estudios serian los siguientes: JAIME GIORDANO, "Defensa de Góngora por un comentarista americano", $A$, 1961, núm. 393, 226-241; RoBERTo J AMEs, "Juan de Espinosa Medrano et la poésie de Góngora", Carav, 1966, núm. 7, 127-140; Eduardo Hopkins, "Poética de Juan de Espinosa Medrano en el Apologético en javor de D. Luis de Góngora", Revista de critica literaria, 7-8 (1978), 103-108. 